\title{
CONSTRUINDO ARGUMENTAÇÃO NA SALA DE AULA: A PRESENÇA DO CICLO ARGUMENTATIVO, OS INDICADORES DE ALFABETIZAÇÃO CIENTÍFICA E O PADRÃO DE TOULMIN
}

\author{
Building up argumentation in classroom: \\ cyclic argumentation, indicators of Scientific Literacy \\ and Toulmin argument pattern
}

\author{
Lúcia Helena Sasseron ${ }^{1}$ \\ Anna Maria Pessoa de Carvalho ${ }^{2}$
}

Resumo: O que subjaz à construção dos argumentos em sala de aula é o tema central deste trabalho. As orientações para a observação deste processo são os trabalhos sobre o papel da fala e dos diferentes discursos em sala de aula, bem como os elementos que estão em jogo quando se pretende alcançar a Alfabetização Científica. Analisamos discussões ocorridas em sala de aula e, a partir dos resultados obtidos, foi possível tecer relações entre estes dois temas de estudo da Didática das Ciências e encontrar indícios da existência de um ciclo por meio do qual as argumentações ganham coerência e completude.

Palavras-chave: Argumentação. Alfabetização científica. Padrão de argumentação de Toulmin.

\begin{abstract}
The focus of this work is the grounds of the arguments' construction in the classroom. The guidelines for observation of this process are the work on the role of speech and the various discourses in the classroom and, also, the elements for understanding if Scientific Literacy is expected in Elementary School. We analyzed discussions in the classroom and from the results could make relations between these two subjects within the study of Science Education and find evidence of a cycle through which arguments gain consistency and completeness.
\end{abstract}

Keywords: Argumentation. Scientific literacy. Toulmin's framework.

\footnotetext{
${ }^{1}$ Licenciada em Física, doutora em Educação. Docente, Departamento de Metodologia de Ensino e Educação Comparada, Faculdade de Educação, Universidade de São Paulo (FEUSP). São Paulo, SP, Brasil.

<sasseron@usp.br>

${ }^{2}$ Licenciada e bacharel em Física, doutora em Educação. Docente, Departamento de Metodologia de Ensino e Educação Comparada, FEUSP. São Paulo, SP, Brasil. <ampdcarv@usp.br>

${ }^{1}$ Av. da Universidade, 308

Cidade Universitária - São Paulo, SP

05.508-040 
Sasseron, L. H.; Carvalho, A. M. P.

\section{Introdução}

Muitos são os trabalhos na área de Didática das Ciências que põem em foco o uso das argumentações em sala de aula ou em outros espaços da formação escolar. Em termos gerais, podemos considerar que são três as principais linhas destes trabalhos: a precisão na definição de uma situação el ou conceito, presente em trabalhos cujo tema central é o uso das palavras e a explicitação das mesmas quando se explora um fenômeno (DAWES, 2004; LEMKE, 1997; SUTTON, 1997); o acréscimo de coerência e coesão no discurso para a compreensão do que se expõe, representado em estudos que discorrem sobre a forma como diferentes discursos utilizados nas aulas atuam em conjunto e as relações existentes entre eles (KRESS; OGBORN; MARTINS, 1998; MARQUEZ; IZQUIERDO; ESPINET, 2003; CARMO, 2006; JIMÉNEZ-ALEIXANDRE; BUGALLO RODRÍGUEZ; DUSCHL, 2000); e a organização do raciocinio na construção e reconstrução de ideias, em cujo escopo encontramos pesquisas que cuidam do modo como os argumentos são construídos em sala de aula e a maneira como as argumentações se desencadeiam aula após aula, debate após debate (CAPECCHI; CARVALHO, 2000; MORTIMER; SCOTTT, 2002; CARVALHO, 2004; TEIXEIRA, 2006; MONTEIRO; TEIXEIRA, 2004).

Estamos cientes ainda de que são diversas as interações discursivas que se passam na sala de aula: elas podem surgir durante a exposição oral de uma ideia por aluno ou por professor; durante a leitura de texto escrito; a elaboração de uma atividade escrita; o trabalho com gráficos e imagens; o uso de recursos audiovisuais, entre outros. Também temos consciência de que são igualmente numerosas as possíveis relações entre saberes que podem ser geradas ou reforçadas durante o processo de ensino e aprendizagem. Neste artigo, temos a intenção de estudar de que modo as argumentações orais em sala de aula são desencadeadas e quais os elementos associados aos argumentos e sua construção.

Temos, como pressuposto, a possibilidade de encontrarmos suportes para compreendermos quais os processos desencadeados na abordagem de um tema científico e quais as relações tecidas para permitirem melhor compreensão do mesmo a partir das ideias em voga ao longo de uma sequência de atividades sobre ciências, das interrelações entre os conhecimentos debatidos e das interações realizadas em sala de aula.

Para estudarmos esta situação, partiremos da aplicação de uma sequência didática em aulas do Ensino Fundamental e buscaremos, ao analisarmos as discussões orais ocorridas, responder às seguintes questões: "De que modo os argumentos se constroem nas discussões em sala de aula? Quais os elementos que subjaz̧em a esta construção?"

\section{Palavras nas aulas de ciências}

Lemke (1998), partindo da ideia da linguagem como prática social, ao estudar textos científicos, observa que diversas formas de linguagem se combinam para cumprir o objetivo de que haja uma comunicação mais eficaz. Para ele, ao construírmos significado, recorremos sempre a gestos, ações e elementos próprios de nossa cultura. $\mathrm{O}$ autor ressalta que há diversas formas de se combinarem informações e relacioná-las, e, portanto, diversas formas possíveis de se construir conhecimento. Lembra ainda que, mesmo que haja diferentes maneiras de se conceberem noções para um mesmo conhecimento, a "[...] cultura é livre para produzir novas restrições a estas combinações” (LEMKE, 1998, p. 2, tradução nossa). 
Com estas discussões, voltamos nossa atenção para a cultura científica e os modos próprios de construção de significados pelos cientistas, ou seja, as características que tornam o discurso científico verdadeiramente científico. De acordo com Lemke:

Para fazer ciência, falar ciência, ler e escrever ciência é necessário burlar e combinar os modos canônicos do discurso verbal, expressão matemática, representação gráfico-visual e operações motoras no mundo natural (incluindo o homem como natural). (1998, p. 3, tradução nossa)

Percebemos que sua atenção recai, agora, sobre as características dinâmicas na linguagem, como forma de potencializar o entendimento de um dado tema. Explorando a ideia de que a fala explicita o raciocínio utilizado pelo aluno, Lemke (1997) afirma que um diálogo científico adquire cada vez mais coerência, tornando-se mais complexo e coeso à medida que novos e mais elementos são adicionados à fala. Neste sentido, o autor ainda ressalta a importância de que o professor esteja atento para os conhecimentos que os alunos já possuem e, consequentemente, para os significados já atribuídos a determinadas palavras e noções.

Assim como Lemke, Sutton (1992) dá ênfase às palavras e ao modo como atribuímos significados a elas. Ressalta a necessidade de se estabelecerem relações entre as palavras, tecendo conexões entre diversos significados que as palavras têm e os tipos de afirmações que podem ser construídas como forma de tornar um conceito passível de ser mais bem compreendido.

A importância do discurso dos alunos nas aulas de ciências como fator contribuinte para uma compreensão mais geral dos processos de aprendizagem das ciências é explorada por Jiménez Aleixandre e Díaz de Bustamante (2003). Os autores ressaltam, também, a importância que depositam em um ensino de ciências capaz de levar os alunos a "fazerem ciência", ou seja, capaz de permitir-lhes proporem e discutirem ideias, avaliarem alternativas, escolhendo entre diferentes explicações.

Jiménez Aleixandre e Díaz de Bustamante (2003) dão destaque à ideia de que a linguagem não é unívoca, lembrando, como já mostramos em Lemke (1997) e Sutton (1992), que diferentes pessoas podem atribuir significados diferentes a uma mesma palavra. Assim, os autores centram sua atenção nos processos por meio dos quais os discursos são construídos, ao invés de se preocuparem apenas com o produto final. Defendem, pois, um ensino de Ciências que não seja somente voltado para a exploração de fenômenos, mas no qual haja possibilidade, também, de que a argumentação seja desencadeada em aula. "Por argumentação entende-se a capacidade de relacionar dados e conclusões, de avaliar enunciados teóricos à luz dos dados empíricos ou procedentes de outras fontes" (JIMÉNEZ ALEIXANDRE; DÍAZ DE BUSTAMANTE, 2003, p. 360, tradução nossa, ênfase no original).

Deste modo, afirmam que a argumentação torna-se cada vez mais forte à medida que novos dados e ideias são trazidos para a fala.

Partindo de propostas similares, Jiménez Aleixandre, Bugallo Rodríguez e Duschl (2000) entendem o raciocínio científico como um processo de tomada de decisões entre evidências e teorias que exige a construção de argumentos defendendo a escolha tomada. Fica claro, então, que, para os autores, a argumentação é uma estratégia de raciocínio em que dados, evidências e crenças e saberes anteriores, assim como na construção do conhecimento científico, são as bases que conduzem à aprendizagem. 
Sasseron, L. H.; Carvalho, A. M. P.

Quando nós colocamos a capacidade de desenvolver um argumento como um objetivo, significa um interesse não somente na resolução de problemas de ciências pelos alunos (nível cognitivo ou estratégico), mas também implica dar atenção aos critérios que conduzem a uma ou outra solução, ao porquê algumas soluções terem sido descartadas, como este processo de comparação é compreendido, quais analogias ou metáforas levaram a este entendimento (nível epistemológico), bem como no acompanhamento dos alunos em sua própria aprendizagem (nível metacognitivo). (JIMÉNEZ ALEIXANDRE; BUGALLO RODRÍGUEZ; DUSCHL, 200, p. 762, tradução nossa, ênfase no original)

Com o objetivo de analisar a estrutura e os elementos dos argumentos utilizados pelos alunos, os autores propõem operações epistemológicas (como a indução, a dedução, a causalidade, o apelo a um exemplo e a consistência com a experiência, por exemplo) como elementos caracterizadores da condução da argumentação e que proporcionam acréscimo de coerência e consistência ao argumento ao longo da apresentação e defesa de uma ideia.

\section{Em foco os argumentos orais}

Entendemos a argumentação como todo e qualquer discurso em que aluno e professor apresentam suas opiniões em aula, descrevendo ideias, apresentando hipóteses e evidências, justificando ações ou conclusões a que tenham chegado, explicando resultados alcançados. Neste sentido, tomando-a em sentido tão amplo, acreditamos haver dois vieses que precisam ser igualmente considerados durante o trabalho em sala de aula: um destes vieses diz respeito à estrutura do argumento e o outro trata de sua qualidade.

Neste trabalho, com o objetivo de identificarmos os elementos em jogo na construção de um argumento, daremos destaque aos aspectos estruturais da argumentação.

\section{O padrão de argumento de Toulmin}

No livro "O uso dos argumentos" (originalmente publicado em 1958), Toulmin (2006) preocupou-se em estabelecer uma interpretação estrutural da argumentação a fim de perceber de que modo sua validade ou invalidade está relacionada dentro do argumento. Seu objetivo era mostrar que nem todos os argumentos podem ser enquadrados na forma "das premissas às conclusões". Para tanto, partiu da questão: "O que, então, está envolvido no processo de estabelecer conclusões mediante a produção de argumentos?” (TOULMIN, 2006, p. 139). Em resposta a esta pergunta, Toulmin apresenta os elementos constitutivos básicos da argumentação e as relações existentes entre eles.

O autor parte da ideia de que uma asserção feita defende uma alegação. Os fatos que apoiam esta alegação são os dados (D) e são os fundamentos com os quais se constrói o suporte à conclusão $(\mathrm{C})$ que se busca apresentar. Deste modo, podemos perceber que a "asserção original apóia-se em fatos apresentados que se relacionem a ela” (TOULMIN, 2006, p. 140). 
É importante salientar que a conclusão, no padrão de Toulmin (2006), representa o final do argumento: não só porque assim aparece na frase, mas especialmente porque se caracteriza por ser o resultado da alegação proposta. Trata-se, também, de um elemento a mais no padrão de argumentação e, assim, não precisa ser autocontida de sentido: o sentido provirá da união dos demais elementos por meio do padrão que Toulmin propõe.

Entre estes outros elementos, existem aqueles que atuam como informações adicionais para relacionar D e C. Estas informações adicionais são, para Toulmin, as garantias (W), e nos permitem entender de que modo o argumento passou dos dados à conclusão. Segundo o autor, as garantias podem ser regras ou princípios, mas não devem ser informações novas. São, portanto, afirmações gerais, hipotéticas; e são as garantias que nos permitem fazer o caminho dos dados às conclusões.

Toulmin ainda se preocupa com casos em que dado, garantia e conclusão não são suficientes para tornar o argumento aceito. Nestes casos, um qualificador modal (Q) surge e se torna a "força que a garantia empresta à conclusão" (TOULMIN, 2006, p. 153). Segundo ele, o qualificador modal é, via de regra, um advérbio que dá aval à conclusão obtida. No viés oposto, as condições de exceção ou refutação (R) fazem com que a garantia perca força e conteste as suposições por ela criadas.

O último elemento apresentado por Toulmin (2006) é aquele que dá aval e autoridade às garantias: é o conhecimento básico (B) que apoia a garantia do argumento.

Seu padrão de argumentação pode ser lido a partir do esquema da Figura 1.

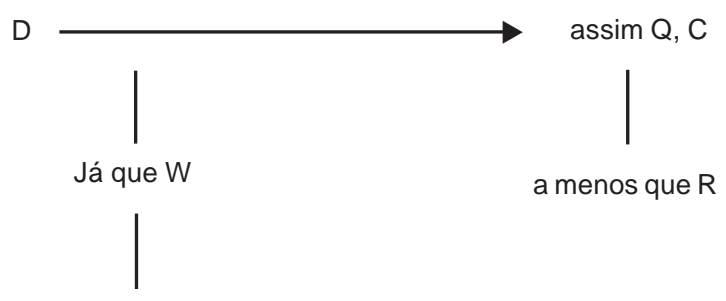

por conta de B

Figura 1. Padrão de argumento (Fonte: TOULMIN, 2006).

\section{Investigando nas aulas de Ciências}

Se são muitos os trabalhos da Didática das Ciências que se preocupam com a argumentação na sala de aula, grande parte deles também aponta o uso de propostas investigativas para a resolução de problemas como fator importante para uma construção satisfatória de 
noções e conceitos científicos (CARVALHO, 2004; TEIXEIRA, 2006; MUNFORD; LIMA, 2007; JIMÉNEZ ALEIXANDRE, 2004; SASSERON; CARVALHO, 2009). Assim como os autores citados, acreditamos que esta forma de trabalho didático pode favorecer a construção de uma visão mais adequada da natureza do trabalho científico.

Pesquisas têm nos indicado a Alfabetização Científica (AC) como elemento norteador na elaboração dos currículos para dar conta de promover um ensino capaz de levar os alunos a investigarem temas das ciências e a discutirem suas inter-relações com a sociedade e o ambiente (FOUREZ, 1994; HURD, 1998; LORENZETTI; DELIZOICOV, 2001; YORE; BISANZ; HAND, 2003; NORRIS; PHILLIPS, 2003; LAUGKSCH, 2000; BINGLE; GASKELL, 1994; BYBEE; DeBOER, 1994).

Não é preocupação central deste trabalho tratar, em profundidade, a AC e as discussões a ela ligadas que demonstrem como o conceito é interpretado e utilizado ao longo dos anos; contudo, interessam-nos suas bases e como elas devem refletir e ser consideradas no planejamento de propostas que objetivem a AC. Nesta perspectiva, durante a revisão de trabalhos sobre a AC, temos percebido a existência de três eixos estruturantes da AC (SASSERON, 2008; SASSERON; CARVALHO, 2008): a compreensão básica de conceitos científicos, a compreensão da natureza das ciências e dos fatores éticos e políticos que circundam sua prática, e o entendimento das relações existentes entre ciência, tecnologia, sociedade e meio ambiente.

Entendemos, ainda, que uma possível maneira de se observar de que modo os conceitos e os elementos do trabalho científico são trabalhados em sala de aula, seja por meio da busca por indicadores da alfabetização científica (SASSERON, 2008; SASSERON; CARVALHO, 2008). Estes indicadores representam ações e habilidades utilizadas durante a resolução de um problema. Alguns destes indicadores estão associados ao trabalho para a obtenção de dados, é o caso do levantamento e do teste de hipóteses em relação a uma situação qualquer; há outros indicadores ligados ao trabalho com estes dados para a classificação, seriação e organização das informacõoes obtidas; também são indicadores da AC: a construção de uma explicação, o uso de justificativa para fundamentar uma ideia e o estabelecimento de previsão sobre o que pode decorrer desta situação; por fim, outros indicadores estão ligados mais diretamente a dimensões epistemológicas da construção do conhecimento, é o caso do uso do raciocínio lógico e do raciocínio proporcional como formas de organizar as ideias que se estão a construir.

Partimos da premissa de que a procura por estes indicadores nos discursos dos estudantes pode fornecer evidências sobre se a AC está em processo entre os alunos estudados. Vale salientar que não entendemos tais indicadores como habilidades hierarquicamente propostas para demonstrar um acréscimo no desenvolvimento cognitivo dos estudantes frente a uma questão. Não acreditamos na existência de tal hierarquia. Mas estamos certas de que possa existir uma ordem temporal na utilização dos indicadores; ordem esta que obedece aos passos que necessitam ser cumpridos para se fazer uma investigação científica.

\section{Um olhar para a sala de aula}

Nossa proposta para explorar as argumentações ocorridas na escola consiste na observação de um conjunto de aulas de Ciências aplicadas em uma escola pública pela professora da turma aos seus alunos. A turma é composta por estudantes que têm entre nove e dez 
anos de idade. A sequência didática utilizada aborda o tema "Navegação e Meio Ambiente", e suas atividades foram aplicadas ao longo de 11 aulas.

Baseamos nossa proposta de ensino em atividades investigativas e partimos do pressuposto de possibilitar, aos alunos, mais do que o trabalho centrado apenas na resolução prática de problemas, o contato com temas científicos quaisquer, desde o uso de sua tecnologia, passando pelas decorrências que tal saber pode trazer. Desta maneira, o trabalho prevê um olhar sobre temas das ciências enfocando também as dimensões sociais e ambientais associadas ao uso destes conhecimentos e dos adventos deles provenientes.

A sequência didática aplicada foi elaborada por uma equipe de cinco pesquisadoras e professoras do LaPEF (Laboratório de pesquisa e Ensino de Física da Faculdade de Educação da USP). Os objetivos centrais que nos nortearam na elaboração e planejamento desta e de outras propostas estão ligados à possibilidade de, desde o início do EF, proporcionar aos alunos possibilidades de se envolverem com problemas das ciências, investigando suas soluções e construindo conceitos a eles associados. Uma vez que as propostas giraram em torno de temas das ciências e de suas relações com a sociedade e com o meio ambiente, além de permitirmos e incentivarmos a participação ativa dos estudantes, outro de nossos objetivos está ligado à promoção do início da AC destes alunos.

Como mencionado, a sequência didática "Navegação e Meio Ambiente" foi o foco de atenção deste estudo. Ela tem início com atividades e discussões sobre a importância da distribuição uniforme de massa em um corpo para sua flutuação: a partir do problema experimental conhecido como "Problema do barquinho" (CARVALHO et al., 1998), faz com que os alunos manipulem folhas de alumínio de tal modo a construir um barquinho que, quando posto em água, consiga carregar o maior número de arruelas de ferro sem afundar. O objetivo é levar os alunos a construírem a relação entre formato da embarcação e a capacidade de carga, desde que se mantenha a distribuição uniforme de massa.

Após isso, os alunos realizam pesquisas e discussões sobre história da navegação e meios de transportes aquáticos.

A partir das discussões dos dados coletados em suas pesquisas, exploramos a temática diferentes tipos de embarcações para diferentes finalidades, e é apresentada, aos alunos, a ideia do lastro como forma de garantir estabilidade às embarcações. Além do aspecto físico do lastro, trabalhamos, com os alunos, os problemas ambientais que podem representar a introdução de espécies de outros habitats em áreas nas quais os navios de carga despejam a água de lastro de seus tanques.

Estas discussões baseiam-se, sobretudo, em evidências que os alunos podem encontrar ao participarem do jogo "Presa e predador"3 e construírem uma tabela com os dados obtidos nesta atividade. A partir da simulação das interações entre os indivíduos de três espécies (plantas, tapitis e jaguatiricas) em uma brincadeira realizada em sucessivas rodadas, é possível construir uma tabela na qual consta o número de indivíduos de cada espécie em cada

\footnotetext{
${ }^{3}$ Este jogo simula a dinâmica das populações e sua proposta foi adaptada do material "Subsídios para implementação de biologia para o $2^{\circ}$ grau”, produzido pelo Cecisp - Cenp em 1980.
} 
rodada. Por meio desta tabela, é possível discutir a dinâmica das populações e a estreita relação existente entre os diferentes seres vivos personagens do jogo. A discussão da possível presença de seres vivos transportados na água de lastro surge como pretexto para se explorar a questão das consequências que pode representar a inserção de seres vivos em um novo local que anteriormente não era por eles habitado.

Todas as aulas da sequência didática foram gravadas em vídeo, e utilizaremos as transcrições dos discursos orais como dados para análise. Os nomes dos alunos são fictícios e tal estratégia foi utilizada com o objetivo de manter preservada a identidade de cada um. A análise aqui apresentada será do tipo qualitativa, em busca de indícios que possam dar conta de nos mostrar como os argumentos são apresentados e construídos pelos alunos.

\section{O jogo "Presa e predador"}

Uma vez que os apontamentos trazidos neste artigo centram-se na análise da aula em que os alunos discutem os resultados do jogo "Presa e predador", explicitaremos aqui alguns detalhes desta dinâmica.

Como dissemos, a intenção desta atividade é trazer à tona a discussão sobre as relações existentes entre diferentes indivíduos de uma cadeia alimentar e as consequências desencadeadas pelo crescimento ou pela diminuição de uma destas espécies.

A atividade é desenvolvida como uma brincadeira pega-pega em que os alunos representam, a cada rodada, o papel dos seres vivos de três espécies diferentes: plantas, tapitis (um coelho brasileiro) e jaguatiricas. Uma rodada deve ter duração média de 10 segundos - tempo suficiente para que cada um dos indivíduos das espécies represente seu papel. Por se tratar de uma brincadeira que envolve rápida movimentação dos alunos, é recomendável que seja realizada em um local amplo e aberto, como, por exemplo, o pátio da escola.

Para dar início ao jogo, sugerimos que a sala seja dividida em três grupos, cada um dos quais representando uma espécie. Não havendo divisão exata do número de participantes pelo número de espécies, deve-se colocar o maior número de alunos entre o grupo dos participantes que representarão as plantas. Para facilitar a dinâmica do jogo, é aconselhável que a distinção entre as espécies seja de fácil visualização: costumamos distribuir crachás de cores diferentes para cada espécie; cada aluno deve ter seu crachá indicando a qual espécie pertence naquela rodada.

O jogo tem regras específicas e cada espécie deve se comportar de acordo com o princípio que lhe é apresentado. Estas leis detalham a busca por alimento própria de cada espécie, bem como os mecanismos utilizados para a sua própria preservação:

Plantas não podem sair do local que estão ao início de uma rodada e podem servir de alimento para os tapitis;

Tapitis devem procurar se alimentar de uma planta a cada rodada; além disso, devem evitar o ataque de seu predador - a jaguatirica - e, para tanto, sua defesa consiste em se agacharem quando estiverem em perigo;

Jaguatiricas não possuem predador em nosso jogo, mas devem procurar se alimentar de sua presa - o tapiti.

Não é permitido a tapitis e jaguatiricas se alimentarem de mais de uma presa por vez. 
Construindo argumentação na sala de aula: ...

Terminada uma rodada, é hora de reorganizar a turma para a seguinte. Isso deve acontecer de acordo com as seguintes regras:

Tapitis e jaguatiricas que não conseguiram alimentos, voltam na próxima rodada como plantas;

Planta que foi devorada por um tapiti volta, na rodada seguinte, como tapiti;

Tapiti que foi devorado por jaguatirica retorna como jaguatirica;

Tapitis e jaguatiricas que se alimentaram, continuam, na rodada seguinte, como seres da mesma espécie.

Ao término de cada rodada, realizadas as devidas alterações de papéis, o professor deve contabilizar o número de indivíduos de cada espécie. Isso permite que seja construída uma tabela com os dados obtidos nas várias rodadas da brincadeira. Esta tabela será essencial para as discussões que devem ser suscitadas no decorrer da aplicação da sequência didática, quando será colocada, em foco, a dinâmica das populações e a estreita relação existente entre os diferentes seres vivos personagens do jogo.

\section{A análise das argumentações}

Selecionamos dois episódios de ensino para serem apresentados neste momento. Os dois ocorreram na décima aula após o início das discussões referentes à sequência didática. Esta aula acontece logo após a realização do jogo e imediatamente após os alunos terem discutido, em pequenos grupos e com a professora, os dados do jogo organizados em tabela. Em específico, trata-se do momento em que alunos e professora leem e discutem o texto de sistematização intitulado "Entendendo o jogo presa e predador". No texto, são relembradas as regras do jogo e menciona-se, também, a necessidade de alimento como uma das condições para a sobrevivência de um ser vivo.

A forma como o texto foi lido ficou a cargo da professora. Ela escolheu que ela mesma faria a leitura do texto em voz alta. A cada pequeno trecho de, no máximo, um parágrafo, a professora parava a leitura e fazia perguntas aos alunos buscando enfatizar as discussões do texto e destacando, uma vez mais, as relações entre as diferentes espécies do jogo "Presa e predador" que já haviam sido discutidas mais detalhadamente na aula anterior, quando do trabalho com a tabela obtida por meio dos dados provenientes do jogo.

\section{Primeiro episódio selecionado}

O primeiro trecho que aqui destacamos ocorreu no início da leitura e discussão do texto "Entendendo o jogo da presa e predador". Neste episódio, percebemos a professora encaminhar a discussão para a retomada das regras do jogo "Presa e predador", pois a atividade central desta aula (a leitura e a discussão do texto) parte destas regras e dos comportamentos observados em sua execução para que sejam construídas relações entre as três espécies de seres vivos participantes do jogo. 
Sasseron, L. H.; Carvalho, A. M. P.

Tabela 1. Primeiro episódio selecionado.

\begin{tabular}{|c|c|c|}
\hline Turno & Falas transcritas & Indicadores \\
\hline 37 & $\begin{array}{l}\text { Professora: (concordando) Continuava tapiti. E a jaguatirica que } \\
\text { se alimentava de tapiti? O que que acontecia na outra rodada? }\end{array}$ & Organizar informações \\
\hline 38 & Luciano: Ela continuava sendo jaguatirica. & Organizar informações \\
\hline 39 & Professora: E o tapiti que tinha sido comido pela jaguatirica? & Organizar informações \\
\hline 40 & Eric: Virava planta. & Organizar informações \\
\hline 41 & Luciano: Virava jaguatirica. & Organizar informações \\
\hline 42 & $\begin{array}{l}\text { Professora: E por que que a planta que era comida pelo tapiti } \\
\text { virava tapiti, e o tapiti que era comido por jaguatirica virava } \\
\text { jaguatirica? Por que que isso acontecia? (pausa) Hum? Por que, } \\
\text { Rogério? }\end{array}$ & \\
\hline 43 & $\begin{array}{l}\text { Rogério: Não sei, mas acho que quando ela come o tapiti, ela } \\
\text { mastiga, mastiga e engole, aí depois o, a, o tapiti vira uma parte } \\
\text { do corpo dela. }\end{array}$ & $\begin{array}{l}\text { Explicação } \\
\text { Levantamento de hipóteses } \\
\text { Previsão } \\
\text { Raciocínio lógico }\end{array}$ \\
\hline 44 & $\begin{array}{l}\text { Professora: (concordando) Muito boa. Vocês ouviram o que o } \\
\text { Rogério falou? }\end{array}$ & \\
\hline 45 & Júnior: Não. & \\
\hline 46 & $\begin{array}{l}\text { Professora: Vou repetir um pouco mais alto. (falando para o } \\
\text { Rogério) . Aí você me corrige se eu falar alguma coisa errada. } \\
\text { Quando... (chamando a atenção de uma aluna), viu, Isabel?... } \\
\text { Quando a jaguatirica, quando a jaguatirica come o tapiti, o tapiti } \\
\text { vai pra dentro da jaguatirica, não é isso?, e aí ele acaba se } \\
\text { tornando um pedaço da jaguatirica, um pouco da jaguatirica, ele } \\
\text { acaba fazendo parte da jaguatirica, não é isso? Daí, ele, ele vai } \\
\text { virar jaguatirica também. E isso acontece com a planta também?, } \\
\text { quando ela é comida pelo tapiti? }\end{array}$ & Organizar informações \\
\hline 47 & Alunos: Sim. & \\
\hline 48 & $\begin{array}{l}\text { Professora: (concordando) A mesma coisa. Quando o tapiti come } \\
\text { a planta, a planta passa a fazer parte do tapiti, daí ele será } \\
\text { também um tapiti. Fala, Isabel. }\end{array}$ & Organizar informações \\
\hline
\end{tabular}

Percebemos que, entre os turnos 37 e 41, as perguntas da professora são retóricas e referem-se explicitamente às regras do jogo. Demanda-se, pois, que os alunos concedam respostas imediatas e sem observações adicionais, o que está de acordo com o objetivo deste momento da discussão: relembrar o que já foi mencionado em sala de aula, pois, assim, serão organizadas as informações até agora debatidas e a discussão poderá avançar com novos tópicos sendo colocados em pauta.

Logo na sequência, no turno 42, a professora deixa de questionar os alunos sobre como cada espécie se comportava ao longo do jogo e lança a pergunta: "E por que que a planta que era comida pelo tapiti virava tapiti, e o tapiti que era comido por jaguatirica virava jaguatirica?". Rogério responde à questão da professora apresentando sua ideia: "Não sei, mas acho que quando ela come o tapiti, ela mastiga, mastiga e engole, ai depois o, a, o tapiti vira uma parte do corpo dela." 
Embora ele mesmo sustente, em sua colocação, não possuir certeza sobre o que diz, sua afirmação é capaz de fornecer uma explicação para a pergunta feita pela professora no turno 42 sobre o porquê das dinâmicas passadas no jogo: "quando ela come o tapiti, ela mastiga, mastiga e engole, ai depois o, a, o tapiti vira uma parte do corpo dela". Sua afirmação demonstra o levantamento de hipótese para a situação e, associada a esta hipótese, Rogério propõe uma previsão relacionada ao futuro desses seres vivos: "aí depois o, a, o tapiti vira uma parte do corpo dela".

Lembrando do padrão de argumentação proposto por Toulmin (2006), percebemos que sua frase se estrutura logicamente, pois Rogério parte de um dado, ou seja, de uma alegação, explicitado quando ele afirma "quando ela come o tapiti". Para obter sua conclusão, ele propõe uma garantia para aquela afirmação: "ela mastiga, mastiga e engole". Tendo demonstrado sua alegação de forma coerente, ele, então, obtém sua conclusão expressa pela sentença: "aí depois o, a, o tapiti vira uma parte do corpo dela".

Neste turno, fica claro o uso de quatro indicadores da AC pelo aluno Rogério: o levantamento de hipótese sobre o fenômeno estudado; uma explicação fornecida ao problema que estão investigando; o uso de justificativa para dar consistência à sua ideia; e o uso do raciocínio lógico possibilitando uma estrutura coesa para o argumento proferido.

Em seguida, no turno 48, à sala toda, a professora ressalta o que Rogério disse. Esta sua ênfase na afirmação do aluno dá aval positivo ao que foi proposto e põe em destaque a sistematização das asserções suscitadas neste momento. Desta maneira, a professora reforça os pontos da discussão ocorrida que julga relevantes e importantes de serem elucidados para a continuação do debate. Essa sua atitude torna-se, então, mais uma maneira de organizar as novas informações para a turma.

\section{Segundo episódio analisado}

Embora tenhamos selecionado os turnos que vão do 81 ao 85 , as discussões mostradas nestes instantes referem-se à leitura de um trecho do texto "Entendendo o jogo Presa e predador", que ocorreu no turno 72. Nesta ocasião são colocadas, em pauta, as últimas regras do jogo "Presa e predador", e é ressaltado o que acontecia com cada umas das espécies ao longo da brincadeira quando se alimentavam ou não. A partir disso, o texto estabelece conexões com a vida de outros seres vivos e a importância da alimentação para a sobrevivência.

Tendo apresentado a leitura deste trecho, nos turnos abaixo vemos a professora pedir aos alunos que pensem sobre o que poderia acontecer com um ser vivo que foi transportado pela água de lastro e que passa a habitar um local com boas condições de sobrevivência e onde não existe seu predador natural.

No turno 81, Luciano afirma uma ideia: a necessidade de predador em um local qualquer.

"É por causa que assim, se ele, por causa que, todo lugar onde tem bicho, precisa ter um predador. Por causa que se não tiver um predador para comer ele, ele vai se alimentar daquela coisa, ai vai ter só daquela espécie, ai a comida vai acabando até acabar. Por isso que precisa de um predador." 
Sasseron, L. H.; Carvalho, A. M. P.

Tabela 2. Segundo episódio selecionado.

\begin{tabular}{|c|c|c|}
\hline Turno & Falas transcritas & Indicadores \\
\hline 81 & $\begin{array}{l}\text { Luciano: É por causa que assim, se ele, por causa que, todo } \\
\text { lugar onde tem bicho, precisa ter um predador. Por causa que se } \\
\text { não tiver um predador para comer ele, ele vai se alimentar } \\
\text { daquela coisa, aí vai ter só daquela espécie, aí a comida vai } \\
\text { acabando até acabar. Por isso que precisa de um predador. }\end{array}$ & $\begin{array}{l}\text { Levantamento de hipótese } \\
\text { Raciocínio lógico } \\
\text { Justificativa } \\
\text { Previsão } \\
\text { Explicação }\end{array}$ \\
\hline 82 & $\begin{array}{l}\text { Professora: Então se a gente... Quem mais tem uma ideia, que } \\
\text { tenha a ver, de relacionar esse jogo da presa e do predador sobre } \\
\text { tudo que a gente discutiu com aqueles seres marinhos lá do } \\
\text { tanque de lastro? Fábio. }\end{array}$ & \\
\hline 83 & Fábio: Todo bicho tem que ter um predador. & Não aparece indicador da AC \\
\hline 84 & $\begin{array}{l}\text { Professora: (concordando) Todo bicho tem que ter um predador. } \\
\text { Luciano, quer completar a ideia? }\end{array}$ & \\
\hline 85 & $\begin{array}{l}\text { Luciano: Quero. Por causa que nem a gente estava estudando lá, } \\
\text { quando um comia o outro, ele virava tapiti ou jaguatirica. Então, } \\
\text { se tiver só daquela espécie ali e não tiver um predador, ele vai } \\
\text { comer aquilo e vai acabar. E lá, o tapiti, ele tinha um predador, } \\
\text { que daí comia ele, aí não ia ficar um monte de tapitis e, e, e, uma } \\
\text { planta. Aí, ele não tinha um predador, esse peixe, e ia comer toda } \\
\text { a comida de lá, aí ia acabar. Aí depois aquela espécie ia morrer. }\end{array}$ & $\begin{array}{l}\text { Organização de informações } \\
\text { Explicação Justificativa } \\
\text { Previsão } \\
\text { Levantamento de hipótese } \\
\text { Teste de hipótese } \\
\text { Raciocínio lógico }\end{array}$ \\
\hline
\end{tabular}

Para reforçar a qualidade desta sua proposição, ele apresenta uma situação na qual surgiriam adversidades devido à extinção ou a inexistência do predador. Podemos notar que seu argumento constrói-se da seguinte maneira: inicialmente, Luciano levanta uma hipótese, baseada na experiência, ao afirmar: "todo lugar onde tem bicho, precisa ter um predador". Em seguida, propõe uma explicação para a hipótese levantada: "se não tiver um predador para comer ele, ele vai se alimentar daquela coisa, ai vai ter só daquela espécie". Sua explicação traz contida uma justificativa ("ele vai se alimentar daquela coisa, aí vai ter só daquela espécie") que corrobora a ideia planejada.

Tendo feito tais construções, Luciano estabelece ainda uma previsão para acontecimentos que podem ocorrer em decorrência do comportamento por ele afirmado: "a comida vai acabando até acabar". É interessante notar ainda que sua previsão recebe uma justificativa: "Por isso que precisa de um predador".

Nesta sua situação hipotética, apoiada nos acontecimentos observados durante o jogo, ficam claros dois argumentos sinalizando o que pode ocorrer caso não haja o predador: enfatiza a necessidade da existência de predadores como condição para que não ocorra um superpovoamento, e coloca em pauta o fato de que uma superpopulação de determinada espécie pode levar à escassez de alimentos. Estas duas possíveis situações ligadas e dependentes entre si unem justificativas suficientes para comprovar sua ideia e deduzir uma dada consequência.

Conciliando todas essas suas sentenças, percebemos que a fala de Luciano demonstra a construção de um modelo explicativo capaz de fornecer subsídios, ainda que parciais, para a necessidade de predadores naturais em todo ambiente.

Podemos perceber que a construção do argumento de Luciano percorre os elementos do padrão de argumento proposto por Toulmin (2006): quando o aluno afirma que "todo lugar 
onde tem bicho, precisa ter um predador", percebemos a apresentação daquele que será o seu dado, a sua alegação. A conclusão de seu argumento aparece no meio de sua fala, quando ele diz: "aí vai ter só daquela espécie". Para chegar até esta finalização de sua ideia, ele apresenta uma garantia expondo que "se não tiver um predador para comer ele, ele vai se alimentar daquela coisa [...] aí a comida vai acabando até acabar".

A rica colocação de Luciano deixa evidente o uso de cinco indicadores da AC: o levantamento de hipótese, a justificativa para os argumentos apresentados, a possibilidade de previsão de um fenômeno a partir de suas colocações, o uso do raciocínio lógico conferindo estrutura coerente à sua exposição e, com a associação de todos estes seus argumentos, podemos notar a construção de uma explicação para a necessidade da existência de predadores.

Logo em seguida, no turno 83, o aluno Fábio expõe a mesma ideia que a proposta por Luciano: "Todo bicho tem que ter um predador."

Sua colocação é uma afirmação sem apresentar quaisquer justificativas para sua colocação. Em sua fala, não encontramos nenhum indicador da $\mathrm{AC}$, no entanto percebemos $\mathrm{o}$ endosso à fala de Luciano, reforçando e reafirmando as colocações dele.

Encerrando este episódio, no turno 85, Luciano complementa as ideias anteriormente expostas.

"Quero. Por causa que nem a gente estava estudando lá, quando um comia o outro, ele virava tapiti ou jaguatirica. Então, se tiver só daquela espécie ali e não tiver um predador, ele vai comer aquilo e vai acabar. E lá, o tapiti, ele tinha um predador, que dai comia ele, ai não ia ficar um monte de tapitis e, e,e, uma planta. Ai, ele não tinha um predador, esse peixe, e ia comer toda a comida de lá, aí ia acabar. Ai depois aquela espécie ia morrer."

Desta fala, percebemos a análise de Luciano para duas situações: a primeira levando em conta especificamente ao jogo "Presa e predador" e as alterações dele decorrentes nas populações de jaguatiricas, tapitis e plantas; e a segunda situação analisada remetendo-se a um peixe, o que nos indica a busca de Luciano por compreender o que ocorrerá a um ser vivo que for transportado na água de lastro de uma embarcação.

Assim como havia ocorrido anteriormente, sua fala tem uma forte estrutura lógica que lhe confere coerência: ele parte de um conhecimento adquirido anteriormente com a experiência do jogo e a organização das informações que possui ao dizer: "quando um comia o outro, ele virava tapiti ou jaguatirica". A partir desta informação, Luciano constrói uma explicação para o problema: "Então, se tiver só daquela espécie ali e não tiver um predador, ele vai comer aquilo e vai acabar." Esta explicação é composta de previsões para outros acontecimentos caso suas ideias sejam validadas: "ele vai comer aquilo e vai acabar". Imediatamente após, Luciano explicita uma situação que é a justificativa de suas afirmações anteriores: "E lá, o tapiti, ele tinha um predador, que dai comia ele, ai não ia ficar um monte de tapitis e, e, e, uma planta". Como desdobramento destas ideias, Luciano realiza o levantamento e o teste de uma hipótese para o caso dos seres vivos que podem ser levados pela água de lastro: "Ai, ele não tinha um predador, esse peixe, $e$ ia comer toda a comida de lá, aí ia acabar. Ai depois aquela espécie ia morrer". Os próprios verbos, conjugados na forma coloquial do futuro do pretérito, já dão evidência da proposição como algo condicional e de que a proposição seja uma nova ideia. Isso se reforça pelo fato de que 
esta sua colocação é totalmente nova no contexto do debate que está sendo travado com a turma nesta aula. A justificativa que dá confiabilidade a sua proposição aparece quando ele diz: "ia comer toda a comida de lá".

Para compreender o padrão utilizado por Luciano ao manifestar seus argumentos, podemos analisar sua proposição por meio do padrão proposto por Toulmin (2006):

Luciano parte do conhecimento básico, expresso pela sentença "quando um comia o outro, ele virava tapiti on jaguatirica", para apresentar sua alegação, seu dado: "se tiver só daquela espécie ali e não tiver um predador". A conclusão a que pretende chegar com tal alegação, Luciano profere na sequência: "ele vai comer aquilo e vai acabar". Para conferir aval à sua conclusão, o aluno apresenta uma condição de refutação ao afirmar: "E lá, o tapiti, ele tinha um predador, que dai comia ele, ai não ia ficar um monte de tapitis e, e, e, uma planta".

Em seguida, estendendo seu raciocínio para outra situação, Luciano apresenta um novo dado, expresso na sentença "Aí ele não tinha um predador, esse peixe", para chegar até sua conclusão: "aí ia acabar. Ai depois aquela espécie ia morrer". Esta conclusão é apoiada em uma garantia sobre o comportamento do peixe caso não haja predador. A garantia é anunciada pela frase "e ia comer toda a comida de lá".

Vemos, portanto, a presença de sete indicadores da AC em sua afirmação: os argumentos que Luciano apresenta provêm de conhecimentos anteriores que são enunciados por ele e que permitem a organização de informações. A partir deles, utilizando o raciocínio lógico para dar coerência às suas afirmações, Luciano constrói uma explicação capaz de permitir que, com ela, seja estabelecida uma previsão. Uma justificativa é apresentada e dá garantia à explicação. Tendo construído estes argumentos, Luciano encontra suporte para proclamar uma nova hipótese e testá-la. O teste desta hipótese não ocorre no nível concreto, mas o aluno, assim como havia feito com a explicação dada anteriormente, apresenta uma justificativa que confere aval a ele.

\section{Algumas considerações após a análise dos dados}

$\mathrm{Na}$ aula 10, para concluir as discussões iniciadas na aula anterior, a atividade central da sequência didática "Navegação e Meio Ambiente" foi a leitura e discussão do texto "Entendendo o jogo presa e predador". Era dada uma nova oportunidade para que ocorresse a compreensão básica de alguns conceitos e termos cientificos envolvidos na exploração do tema destas aulas. Além disso, com a discussão das informações existentes no texto, características próprias da natureza das ciências poderiam ser trazidas à tona durante a apresentação das ideias. Ao final do texto, é apresentada aos alunos, de maneira clara e direta, a necessidade de que, em um dado local, haja presas e, também, predadores, pois a inexistência de predador para um determinado ser vivo pode levar a que aquele lugar sofra com alterações no número de indivíduos daquela espécie e de outras a ela associadas. Neste sentido, ao explorar esta informação do texto relembrando discussões sobre a "migração humanizada" incitada pelo uso de água em tanques de lastro de embarcações que viajam o globo terrestre, a professora tornou possível, também, que algumas relações entre ciência, tecnologia, sociedade e meio ambiente fossem tecidas a partir da avaliação dos impactos dos conhecimentos até agora discutidos nas diferentes esferas consideradas. 
Em nossa análise, notamos a retomada dos dados existentes e a ordenação dos mesmos antes que construções de relações pudessem ser estabelecidas. No entanto, o que mais chama a atenção nos episódios apresentados são as próprias explicações construídas pelos alunos e os elementos trazidos para justificarem as mesmas e preverem eventos associados. Percebemos que estas construções baseiam-se, sobretudo, nas discussões já realizadas até o momento sobre os temas da sequência didática, e demonstram um alto grau de coerência interna no que diz respeito à conexão das informações disponíveis. São respostas que extravasam as ideias pensadas no jogo e refletem a compreensão dos conceitos explorados ao demonstrarem a extensão das ideias para novas situações não mencionadas anteriormente. Mostram, então, habilidades investigativas sendo utilizadas pelos alunos para comentarem e estudarem situações além das propostas.

Ao constatar a presença e o aparecimento dos indicadores da AC durante a sequência dos turnos analisados, temos clara a existência de um ciclo argumentativo envolvendo a divulgação da construção do entendimento de um conceito ou de um tema pelos alunos. Entendemos este ciclo argumentativo como a forma por meio do qual as argumentações se desencadeiam e a maneira como as relações entre diferentes dados e variáveis são estabelecidas.

Percebemos que o primeiro passo dado no trabalho de investigação é o cuidado com os dados existentes: de posse das informações obtidas durante uma atividade prática, durante a leitura de um texto, por meio da discussão com os pares ou pela recorrência a conhecimentos previamente adquiridos, é preciso ordená-las convenientemente para que se torne explícita a importância de cada uma em cada momento e situação.

O trabalho com os dados/informações disponíveis constituiu o segundo passo do ciclo por meio do qual as argumentações se desenvolviam: momento em que variáveis para o problema começaram a ser definidas. Observamos que, no decorrer deste passo, as primeiras hipóteses começaram a ser mencionadas. Ao mesmo tempo, justificativas foram acrescentadas às afirmações feitas, bem como apareceram algumas previsões sobre o que poderia ocorrer caso a ideia arquitetada se sustentasse. As justificativas e as previsões desempenham o interessante papel de demonstrar certezas e contrastes e, com isso, constroem o espaço para as informações relevantes e significativas naquela dada investigação e as conexões que elas têm com as demais.

Por fim, o ciclo argumentativo que observamos chega às explicações propriamente ditas. Neste momento, todas as construções feitas anteriormente são utilizadas com o objetivo de se estabelecerem conexões entre as informações e as variáveis, pois, deste modo, obtém-se uma ideia mais concreta de como os efeitos vistos e/ou previstos ocorrem. É possível, então, chegar a construções lógicas, objetivas e racionais entre causas e efeitos e, portanto, possuir conhecimentos por meio dos quais os benefícios e prejuízos de cada situação sejam também investigados.

Uma característica interessante das argumentações merece ser destacada e comentada aqui: temos percebido uma relação bastante intensa e profícua entre o aparecimento e uso dos indicadores da AC e o padrão de argumentação de Toulmin (2006).

Em linhas gerais, observamos que o trabalho com as informações de que os alunos dispõem (seja no intuito de buscar a sua organização, seriação ou classificação) tem o papel de deixar em evidência o conbecimento básico que alicerçará as ideias e as argumentações dos estudantes. Este trabalho com as informações é de grande importância, em se considerando uma 
investigação científica, uma vez que possibilita a percepção e compreensão em relação às variáveis em cena. Deste modo, abre-se a possibilidade para que alegações comecem a se desenhar. Quando surge esta alegação, chamada por Toulmin (2006) de dado, percebemos o uso de indicadores relacionados ao estabelecimento de hipóteses que são trazidas para a discussão como maneira de apresentar a ideia construída ou a se construir.

No padrão de Toulmin (2006), percebemos a conclusão diretamente relacionada ao dado apresentado, embora outros elementos entrem em jogo. Em referência aos indicadores da $\mathrm{AC}$, nossa proposta surge em compreendermos uma explicação como ligada à hipótese apresentada. A diferença que concebemos entre a conclusão de Toulmin e a explicação como indicador da AC é que a conclusão, conforme mencionamos anteriormente, não precisa apresentar sentido em si só, pois é a análise do padrão como um todo que a legitimará; por outro lado, a explicação caracteriza-se por revelar as relações construídas ao longo de uma colocação e, neste sentido, pode ser pontual, ainda que importante e necessária para a compreensão da ideia completa que se enuncia.

Os elementos que aparecem associados a uma e a outra, à conclusão e à explicação, têm como função principal, dentro do argumento, assegurar maior validade e autenticidade à proposição. Neste sentido, percebemos que o uso do indicador justificativa pode ser tomado como o uso de garantias dentro do padrão de Toulmin (2006), quando a justificativa corrobora positivamente a ideia apresentada, ou pode ser visto como a apresentação de uma condição de refutação, caso ela conteste a alegação inicial. Por fim, Toulmin (2006) elenca os qualificadores modais como mais um elemento de seu padrão de argumento. Eles são, via de regra, advérbios que dão aval à conclusão obtida. Pensando nos indicadores, percebemos que este papel cabe às previsões que se estabelecem com referência à hipótese trazida para a discussão.

A importância destas colocações, em nossa visão, reside em que, estudando o modo como os argumentos se constroem em sala de aula e percebendo o ciclo por meio do qual um argumento torna-se cada vez mais completo e coerente, poderemos encontrar bases a partir das quais seja possível considerar de que maneira uma discussão pode ser desencadeada e encaminhada em sala de aula pelo professor. Não se trata somente de levá-lo a ter consciência da necessidade da argumentação como fator que leve os alunos a uma construção de conhecimentos que lhes tenha mais significado; trata-se, também, de permitir ao professor que reconheça a necessidade de passos subsequentes durante as discussões e, assim, trabalhe para estimular o aparecimento dos mesmos em cada momento da aula.

\section{Referências}

BINGLE, W. H.; GASKELL, P. J. Scientific literacy for decision making and the social construction of scientific knowledge. Science Education, Hoboken, v. 78, n. 2, p. 185-201, 1994.

BYBEE, R.W.; DeBOER, G. E. Research on goals for the science curriculum. In: GABEL, D. L. (Ed.). Handbook of research in science teaching and learning. New York: McMillan, 1994. p. 384. 
Construindo argumentação na sala de aula: ...

CAPECCHI, M. C. V. M.; CARVALHO, A. M. P. Argumentação em uma aula de conhecimento físico com crianças na faixa de oito a dez anos. Investigações em Ensino de Ciências, Porto Alegre, v. 5, n. 2, p. 171-189, 2000.

CARMO, A. B. A linguagem matemática em uma aula experimental de física. 2006. 136f. Dissertação (Ensino de Ciências - Modalidade Física) - Instituto de Física, Universidade de São Paulo, São Paulo, 2006.

CARVALHO, A. M. P. Building up explanations in physics teaching. International Journal of Science Education, London, v. 26, n. 2, p. 225-237, 2004.

CARVALHO, A. M. P.; VANNUCCHI, A.I.; BARROS, M. A.; GONÇALVES, M. E. R.; REY, R. C. Ciências no Ensino Fundamental: o conhecimento físico. São Paulo: Scipione, 1998.

DAWES, L. Talk and learning in classroom science. International Journal of Science Education, London, v. 26, n. 6, p. 677-695, 2004.

FOUREZ, G. Alphabétisation scientifique et technique: essai sur les finalités de l'enseignement des sciences. Bruxelles: DeBoeck-Wesmael, 1994.

HURD, P. D. Scientific literacy: new minds for a changing world. Science Education, Hoboken, v. 82, n. 3, p. 407-416, 1998.

JIMÉNEZ ALEIXANDRE, M. P. La catástrofe del prestige: racionalidad crítica versus racionalidad instrumental. Cultura y Educación, Madrid, v. 16, n. 3, p. 305-319, 2004.

.; DÍAZ DE BUSTAMANTE, J. Discurso de aula y argumentación en la clase de ciências: cuestiones teóricas y metodológicas. Enseñanza de las Ciencias, Barcelona, v. 21, n. 3, p. 359-370, 2003.

.; BUGALLO RODRÍGUEZ, A.; DUSCHL, R. A. "Doing the lesson" or "doing science": argument in high school genetics. Science Education, Hoboken, v. 84, p. $757-792,2000$.

KRESS, G.; OGBORN, J.; MARTINS, I. A sattelite view of language: some lessons from science classrooms. Language Awareness, London, v. 7, n. 2, p. 69-89, 1998.

LAUGKSCH, R. C. Scientific literacy: a conceptual overview. Science Education, Hoboken, v. 84, n. 1, p. 71-94, 2000.

LEMKE, J. L. Aprender a hablar ciencia. Barcelona: Paidós, 1997.

Multiplying meaning: visual and verbal semiotics in scientific text. In: MARTIN, J. R. E.; VEEL, R. (Ed.). Reading science: functional perspectives on discourses of science. London: Routledge, 1998. p. 87-113.

LORENZETTTI, L.; DELIZOICOV, D. Alfabetização científica no contexto das séries iniciais. Ensaio: Pesquisa em Educação em Ciências, Belo Horizonte, v. 3, n. 1, p. 37-50, 2001. 
Sasseron, L. H.; Carvalho, A. M. P.

MÁRQUEZ, C.; IZQUIERDO, M.; ESPINET, M. Comunicación multimodal en la clase de ciencias: el ciclo del agua. Enseñanza de las Ciencias, Barcelona, v. 21, n. 3, p. 371-386, 2003.

MONTEIRO, M. A. A.; TEIXEIRA, O. P. B. Uma análise das interações dialógicas em aulas de ciências nas séries iniciais do ensino fundamental. Investigações em Ensino de Ciências, Porto Alegre, v. 9, n. 3, p. 243-263, 2004.

MORTIMER, E. F.; SCOTT, P. Atividade discursiva nas salas de aula de ciências: uma ferramenta sociocultural para analisar e planejar o ensino. Investigações em Ensino de Ciências, Porto Alegre, v. 7, n. 3, p. 283-306, 2002.

MUNFORD, D.; LIMA, M. E. C. C. Ensinar ciências por investigação: em que estamos de acordo? Ensaio: Pesquisa em Educação em Ciências, Belo Horizonte, v. 9, n. 1, p. 72-89, 2007.

NORRIS, S. P.; PHILLIPS, L. M. How literacy in its fundamental sense is central to scientific literacy. Science Education, Hoboken, v. 87, n. 2, p. 224-240, 2003.

SASSERON, L. H. Alfabetização científica no ensino fundamental: estrutura e indicadores deste processo em sala de aula. 2008. 261f. Tese (Doutorado em Educação) Faculdade de Educação, Universidade de São Paulo, São Paulo, 2008.

O ensino de ciências para a alfabetização científica: analisando o processo por meio de argumentações em sala de aula. In: NASCIMENTO, S. S.; PLANTIN, C. (Orgs.). Argumentação e ensino de ciências. Curitiba: CRV, 2009. p. 139-164.

SASSERON, L. H.; CARVALHO, A. M. P. Almejando a alfabetização científica no ensino fundamental: a proposição e a procura de indicadores do processo. Investigações em Ensino de Ciências, Porto Alegre, v. 13, n. 3, p. 333-352, 2008.

SUTTON, C. Ideas sobre la ciencia e ideas sobre el lenguaje. Alambique: Didactica de las Ciencias Experimentales, Barcelona, v. único, n. 12, p. 8-32, 1997.

Words, science and learning. Buckingham: Open University Press, 1992.

TEIXEIRA, F. M. Fundamentos teóricos que envolvem a concepção de conceitos científicos na construção do conhecimento das ciências naturais. Ensaio: Pesquisa em Educação em Ciências, Belo Horizonte, v. 8, n. 2, p. 121-132, 2006.

TOULMIN, S. E. Os usos do argumento. 2. ed. São Paulo: Martins Fontes, 2006.

YORE, L. D.; BISANZ, G. L.; HAND, B. M. Examining the literacy component of science literacy: 25 years of language arts and science research. International Journal of Science Education, London, v. 25, n. 6, p. 689-725, 2003.

Artigo recebido em maio de 2010 e aceito em dezembro de 2010. 